NASA Technical Memorandum 107260

AIAA-96-4439

\title{
Potential Commercial Applications From Combustion and Fire Research in Space
}

Robert Friedman and Valerie J. Lyons

Lewis Research Center

Cleveland, Ohio

Prepared for the

1996 Space Processing and Technology Conference

sponsored by the American Institute of Aeronautics and Astronautics

Huntsville Alabama, September 24-26, 1996

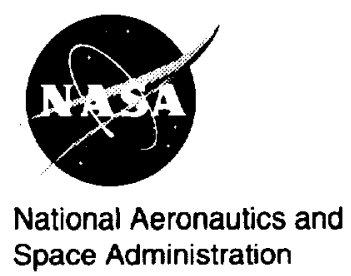


. 


\title{
Potential Commercial Applications From Combustion And Fire Research in Space
}

\author{
Robert Friedman and Valerie Lyons \\ NASA Lewis Research Center; Cleveland, OH, 44135
}

\begin{abstract}
The near-zero (microgravity) environment of orbiting spacecraft minimizes buoyant flows, greatly simplifying combustion processes and isolating important phenomena ordinarily concealed by the overwhelming gravity-driven forces and flows. Fundamental combustion understanding -the focus to date of the NASA microgravity-combustion program-has greatly benefited from analyses and experiments conducted in the microgravity environment. Because of the economic and commercial importance of combustion in practice, there is strong motivation to seek wider applications for the microgravity-combustion findings. This paper reviews selected technology developments to illustrate some emerging applications. Topics cover improved fire-safety technology in spacecraft and terrestrial systems, innovative combustor designs for aerospace and ground propulsion, applied sensors and controls for combustion processes, and self-sustaining synthesis techniques for advanced materials.
\end{abstract}

\section{Introduction}

Combustion reactions are the dominant mode of energy production for transportation, electric power generation, industrial furnaces, and habitat heating. Combustion is the principal reaction in the creation of many commodities, such as the refining of metals or the synthesis of plastics and ceramics. Combustion is also essential to a wide range of industrial operations, including process heating, pollution control, waste incineration, cutting, brazing, and welding.

Access to the non-convective, microgravity environment in orbiting and ballistic spacecraft or in ground-based, free-fall facilities has proven to be highly advantageous for combustion research.' In microgravity, buoyancy-induced flows are nearly eliminated, permitting the isolation of normally obscured forces and flows, the creation of simplified symmetries (isolated fuel particles, for example), and the expansion of experimental time and length scales without the development of disturbances. ${ }^{2}$

The application of fundamental knowledge in combustion science offers great benefits to combustion-derived technology. An immediate advantage of microgravity research is in spacecraft designs and operations, namely, the improvement of fire-safety procedures based on the understanding of the nature of fires in space. ${ }^{3}$ Because of the importance of combustion in practice, a wide range of terrestrial uses for the microgravity-combustion-science data is also foreseen. The exploitation of these applications is now the responsibility of a new Center for Commercial Applications of Combustion in Space (CCACS). The CCACS is a jointly funded NASA/university/industry consortium located at the Colorado School of Mines. The Center has already identified several technology areas with recognized potential for commercialization, namely: 1) fire safety, 2) combustors, 3) sensors and controls, and 4) advanced materials.

This paper reviews the status of practical applications of combustion and fire research in space through a summary of combustion-science results in selected fields of solid-surface combustion, droplet combustion, and soot formation, and through descriptions of emerging technology in the identified areas of commercialization.

\section{Combustion and the Space Environment}

Orbiting space vehicles are in a state of near-equilibrium with a balance of centrifugal and gravitational forces that produces a weightless, or microgravity, environment. This condition is of great value to scientific investigations because the non-convective environment simplifies the study of many physical, transport, and reaction phenomena. ${ }^{1}$ For example, terrestrial, or normal-gravity, combustion is strongly affected by the buoyant upward flow of hot, lowdensity combustion products and the induced entrainment of fresh oxygen into the flame zone. In microgravity, this 
natural-convective flow is greatly reduced, if not entirely absent, enabling the detailed investigation of forces or phenomena normally overwhelmed by the strong buoyant flows. Microgravity allows the creation of idealized boundaries or conditions, such as the isolation of single or interacting particles or droplets. Microgravity also permits experimentation with expanded spatial and time scales, because the onset of turbulent disturbances can be delayed. ${ }^{2}$

Microgravity combustion is now well established as a scientific field, and a wide range of microgravity-combustion models and analyses have been developed. Essential to the support of these theories is experimental verification. While spaceflight is the obvious venue for microgravity experimentation, low-gravity experiment opportunities are not limited to those on (rather infrequent) spacecraft or sounding-rocket missions. Indeed, most microgravity-combustion experimentation has been conducted, with remarkable success, in short-duration airplane, drop-tower and laboratory simulations. ${ }^{4}$

\section{Selected Microgravity-Combustion Test Results}

\section{Scope of Studies}

In microgravity, combustion may occur in near-quiescent conditions, since buoyancy-induced flows are negligible. Moreover, when a forced air flow is superimposed on the combustion zone in microgravity, combustion may proceed with controlled flow at velocities ranging from zero to those greater than the reference (normal-gravity) buoyant flow rate, either in the direction of, or in opposition to, the flame spread.

Analytical and experimental microgravity-combustion research conducted over the past three decades or more has investigated combustion in varied systems, such as premixed and diffusing gases, liquid droplets and pools, solid surfaces, and mixed phases. ${ }^{2}$ Information derived from any of these microgravity-combustion modes can ultimately be valuable for commercial applications. At least three of the combustion phenomena, solid-surface combustion, droplet combustion, and soot production, are recognized as having great potential for immediate application. These selected processes are reviewed in the following sections.

\section{Solid-Surface Combustion}

Fire-safety technology for spacecraft can benefit from the knowledge of ignition and flame spread along solid surfaces, such as plastic panels, wire bundles, circuit boards, paper sheets, clothing, blankets. Despite strict efforts to limit the quantities and spacing of flammable materials and to control ignition sources, certain fire scenarios have some probability of occurrence in space operations. ${ }^{3}$ For example, thermally stressed components may be prone to overheating and ignition, since the near-absence of naturalconvective flows in microgravity greatly reduces air cooling. Again, aerosol clouds or fluid leaks may persist in the atmosphere as potential fire hazards, since settling and dispersion are very slow. Finally, smoldering, a low-temperature non-flaming reaction and possible fire precursor, may initiate readily in the absence of natural convection in spacecraft.

Once ignition occurs in a microgravity environment, however, the resulting flame may not propagate because of the lack of induced flow of oxygen into the flame zone under quiescent conditions. Space experiments have demonstrated this self-extinguishment for fires initiated over certain surfaces, such as wire insulations or thick materials. ${ }^{6,7}$ On the other hand, experiments on thin fuels (paper, for example) show that slow but uniform flame spread is possible in quiescent microgravity. In all of these fire situations, however, the addition of low-speed forced-air flows (of the order perhaps of spacecraft ventilation) can increase the flammability and rate of flame spread. Forced-flow flame spread may, in fact, attain rates comparable to, and possibly exceeding, those in corresponding normal gravity. ${ }^{8}$

The microgravity flame appearance also differs from that associated with conventional, normal-gravity combustion. Flames observed over thin materials are sketched in figure 1. Typically, the microgravity flames are larger, dimmer, and stand off further from the fuel surface, compared to their normal-gravity counterparts.' Other distinguishing features of microgravity flames in gaseous, liquid, and solidphase systems are described in the literature. ${ }^{1,210}$ Investigators report that, in many instances, microgravity flames in quiescent, standard-air conditions are so pale that they are difficult to observe. ${ }^{7}$ Visibility is greatly enhanced under conditions of forced-air flows or high-oxygen concentrations, where microgravity flames are typically brighter and yellow in color. 
The visible appearance of the incipient fire is, of course, ane of the key "signatures" for the remote detection of fires and for alarm criteria. Other common signatures are those of the radiant, gaseous, and particulate (smoke) emissions from flames. These characteristics are often quite different in microgravity compared to normal gravity, possibly altering the criteria and sensitivities for early-waming detection of fires.

\section{Droplet Combustion}

Combustion of sprays of liquid droplets is a common process in propulsion systems and power-generating equipment. A thorough understanding of this combustion process is important for analyses and modeling to promote designs with efficient combustion and reduced exhaust emissions. The isolation of droplets for research is very difficult on Earth because of the motions and distortions caused by the buoyancy-induced flows and forces, and such studies must be limited to relatively small droplets. In microgravity, near-spherical droplets can be generated and maintained for idealized studies of their ignition and flame behavior. The range of microgravity droplet-combustion research covers the burning of pure- and multi-component fuel droplets, in single, double, and multiple-droplet arrays, and in quiescent or low-speed air-flow environments (often stabilized on fibers). Most important, the microgravity environment permits the generation, isolation, and observation of representative droplets, as large as 2 to $6 \mathrm{~mm}$ in diameter. ${ }^{2}$

Fig. 2 illustrates the appearance of typical burning droplets in quiescent and forced-flow microgravity. The quiescent droplet is surrounded by a soot shell and a concentric flame. The soot shell may not be visible under forced flow. Hydrocarbon-droplet combustion initiates with bright, sooty flames, which become less luminous with time. The flame luminosity increases with forced air flow, similar to the phenomena observed with solid-surface flames. Disruptive, almost explosive, burning is noted for bi-component mixtures with greatly differing component volatilities. This behavior results from the expansion of the more volatile fuel as a "bubble" through the shell of the less volatile fuel. $^{2}$

\section{Soot Formation}

Soot is an aggregate of solid, carbonaceous pyrolysisand combustion-product particles. Soot has a high radiative emissivity, and it substantially increases the visibility of, and the radiative transport from, flames. Hence, bright, sooty flames are desirable for efficient energy extraction in furnaces and power equipment. In contrast, soot-enhanced radiation is undesirable in film-cooled propulsion systems, causing decreased life in jet-engine combustion liners, for example. Soot, itself, is of value for the manufacture of carbon black and its products.

Due to minimal buoyant flow, soot residence times in the microgravity combustion zone are relatively long, and consequently soot-particle concentration and morphology vary from these characteristics in normal gravity. Solid-surface flames are nearly soot-free in quiescent air , but sooting increases if the atmospheric oxygen concentration, total pressure, or both are increased. ${ }^{10}$ On the other hand, microgravity gaseous and liquid-droplet flames, even in quiescent environments, are often sootier than in normal gravity. ${ }^{11,12}$

Microgravity conditions greatly aid the isolation and collection of soot particles. Statistical analyses of particles collected from burning wire insulations indicate that both primary soot particles and their aggregates are several times larger in microgravity than in normal gravity. ${ }^{13}$ An example is illustrated in the photographs of fig. 3, which compare soot aggregates collected from gaseous diffusion-flame burners. The typical aggregate in microgravity is larger and is clearly composed of more primary particles.

The differences in soot evolution and characteristics in microgravity have practical significance not only for power and pollution applications but also for fire safety through smoke detection. For optimum sensitivity and false-alarm rejection, smoke detectors are tuned for the expected particle-size distribution. Obviously, the set points for spacecraft smoke detectors can differ from those of typical terrestrial smoke detectors. These practical differences are now under investigation in a spacecraft experiment, ${ }^{14}$ illustrated in fig. 4. The study, the Comparative Soot Diagnostics experiment, determined the response of an ionization detector (Shutrle model) and a photoelectric detector (International Space Station prototype) to smoke emissions from several reference fires in microgravity. Initial data from a Shuttle mission in early 1996 showed that the detectors respond rapidly, as expected, in microgravity. Detailed analyses of the detector sensitivities to a range of soot volume fractions and aggregate sizes are still in progress. 


\section{Survey of Combustion Applications and Opportunities}

\section{Topics of Interest}

The value of analytical and experimental data from microgravity-combustion studies to specific commercial applications has been recognized for some time. A significant survey was conducted in 1988 to identify institutional and industry interest in combustion experiments for the Shuttle and (at that time) the conceptual Space Station. ${ }^{\text {Is }}$ The survey was aimed at obtaining a consensus of experiment definitions, and it was organized into topics or interest groups, namely, those of fire safety for space applications, fire safety for terrestrial applications, propulsion and power, industrial burners, and pollution control. Table 1 is a summary of the major applications that were related to space experiments, as determined by the survey for each of the interest groups. The topic of industrial burners is included in propulsion and power.

Another review was conducted independently by one of the authors. This review evaluated the potential for commercial applications according to combustion modes, namely, those of lean premixed combustion, droplet combustion, soot formation and agglomeration, smoldering and flame spread, and combustion synthesis of novel materials. This review provided the combustion-science bases for the technology areas to be pursued by the new Center for Commercial Applications of Combustion in Space (CCACS), cited earlier. Table 2 is a summary of the potential applications identified in the evaluation, listed by combustion mode. A notable addition to the earlier technologies shown in Table 1 is that of the procuction of new materials through combustion synthesis.

The following sections present potential commercialization opportunities according to product focus groups established by the CCACS.

\section{Fire Safety}

Current spacecraft fire-protection designs and operations are based on terrestrial standards and testing, although there is a growing awareness of the need to apply microgravity-combustion knowledge to improve and optimize spacecraft fire safety. ${ }^{3}$

The first line of spacecraft fire-safety defense is in prevention, through strict material selection, low electricalwire current ratings, fusing, and electrical grounding.
Acceptable materials are those passing a severe flamespread-resistance test, which obviously must be performed in normal gravity. Some flammable materials (paper, film, form, toweling) are necessary exceptions, and their presence in spacecraft is controlled through limited inventory and starage containment. The fire-resistance tests in normal gravity are assumed to represent worst-case scenarios. Research indicates, however, that this safety factor is not necessarily dependable with respect to microgravity flammability. As noted, some materials and ventilation conditions may promote flame spread in microgravity to rates that equal or exceed those in reference normal-gravity environments. ${ }^{8.16}$ Flammability testing of representative materials in microgravity environments on any large scale is impractical. Thus, one aim of microgravity-combustion research is to develop models and data for the prediction of material flammability in ventilated microgravity from correlations of normal-gravity acceptance-test results.

Microgravity research may also assist the development of commodity materials with improved fire and pyrolysis resistance. One example is polytetrafluoroethylene (PTFE) polymer, which is widely used as a wire insulation in spacecraft and aircraft. The degradation of PTFE upon overheating generates toxic gases and ultrafine particles that are hazardous to the lungs. ${ }^{17} \mathrm{New}$ formulations of this polymer that may resist this degradation are under investigation.

The second line of fire protection is the detection and suppression of incipient fires. In space, fire-threatening incidents, none leading to actual fires, have in all cases been detected by the senses of the crew. ${ }^{5}$ Modern spacecraft are equipped with automatic smoke detectors, which are adaptations of standard terrestrial designs. Studies of smoke density and soot characteristics from microgravity fires are in progress to improve the sensitivity and alarm criteria for space smoke detectors. These studies may also prove valuable for improved designs and operational criteria in terrestrial smoke detectors, in their ability to isolate, collect, and analyze smoke constituents.

There have been no incidents in U.S. spaceflight missions requiring active fire suppression. Fire extinguishers are carried on all current human-crew spacecraft, nonetheless. The Shuttle has both portable and remotely actuated fire extinguishers, charged with Halon 1301 (fig. 5). Most of the inhabited modules of the International Space Station, now in construction, will be equipped with portable fire extinguishers charged with carbon dioxide. Exceptions 
are the Russian cabins, which carry a mixed-phase foam agent, and the decompression-trearment chamber, which may carry nitrogen. Spacecraft fire-suppression system designs and operations most likely could be standardized if research data were available on optimum physical dispersion, suppression effectiveness, and post-fire cleanup in microgravity. Suppression experiments with adequate time and physical scales to demonstrate practical fire control are in the planning stages.

New fire suppression agents must be developed for both space and terrestrial applications that have: 1) low atmospheric ozone-depletion potential; 2) low globalwarming potential; 3) low toxicity; and 4) the potential, preferably, to be a "drop in" replacement for Halons (similar vapor pressure, viscosity, etc.) One interesting alternative under investigation is a new use of old technology - water, formed into a very fine mist. ${ }^{18}$

\section{Combustors}

Recent efforts in NASA aeropropulsion research in combustion focus on reducing emissions from gas turbines. ${ }^{1920}$ The reduction of exhaust pollutants such as $\mathrm{NO}_{z}$, $\mathrm{CO}$, umburned hydrocarbons, aerosols, and soot requires an in-depth knowledge of the combustion process. Fundamental combustion science obtained by microgravity research has application in this area by providing information on droplet burning and soot formation, as described previously. This information can be used to assist in the design of low-emission fuel injectors. Experimental data can be used directly to determine fuel spray effects on emissions, or they can validate advanced combustor codes to aid future design efforts. Of particular interest currently is supercritical droplet combustion, which has application to high-pressure combustors in both rocket motors and advanced aircraft engines.

There are several other commercial-product development areas related to combustors that can be linked to potential microgravity-combustion-science research. Particle coalescence and agglomeration can be studied in a simplified flow field in microgravity, where drag can be decoupled from other parameters affecting growth. A better understanding of the particle-formation process may increase the collection efficiencies of electrostatic precipitators for submicron particles. The combustion of tiny suspended coal particles in a microgravity environment can enable the study of the major processes involved in pro- ducing fly ash. Microgravity, which allows a surface-initiated reaction to transition to a homogeneous reaction without the interference of buoyancy, will also aid the study of catalytic combustion, a useful means of reducing emissions from many combustion systems. Also, the use of combustion synthesis to create new, uniformly-porous materials, a subject to be discussed later, will promote the development of improved catalytic substrates.

An indirect application of microgravity-combustion research, recently reported, is that of an apparatus developed for the study of premixed conical flames in upward and downward gravity and in microgravity. ${ }^{21}$ A stabilizing ring was invented to maintain an extremely lean flame for the visualization studies. This device, now patented, is available for commercial license as a residential and industrial gas-burner component, permitting stable, efficient combustion at lean fuel-air ratios for greatly reduced $\mathrm{NO}_{x}$ emissions. 22

\section{Sensors and Controls}

The application of measurement techniques derived in space studies to scientific and commercial purposes on Earth is among the recognized benefits of the space program. The latest NASA Spinoff magazine, for example, cites a number of products, such as optical and radiation sensors, computer enhancement techniques, strain gages, and fiber-optic transmitters, all derived directly or indirectly from spacecraft instrumentation. ${ }^{23}$

Microgravity-combustion research has promoted advances in diagnostic techniques, primarily because of the need for non-perturbing, rapid-response measurements of flame appearance, velocity, temperature, and chemical species in severe environments. The observation of flames often requires image enhancements because the flames are barely visible or weakly radiant. Drop-tower experiments require small, yet rugged instrumentation capable of withstanding large deceleration forces upon recovery at the bottom of the drop. Space-based experiments need small, reliable, light-weight instrumentation. All of these features would be beneficial in other applications, such as aircraft or automotive engine instrumentation.

The commercial development of diagnostic techniques derived from microgravity-combustion research is as yet quite limited, although a recent survey of imaging methods describes a wide variety of promising technology. ${ }^{24}$ One product that is now entering commercial production is a 
line-absorption-spectroscopy instrument originally developed for microgravity chemical-species measurements and tested in ground-based microgravity facilities. The instrument is now promoted as an on-line analyzer for incustrial smoke control.

The new CCACS is focusing initial efforts on developing three products in the sensors and controls area: 1) a demodulating camera for a diode-laser Raman system; 2) a compact particle-imaging velocimetry (PIV) system; and 3) an emission-based sensor for species concentrations (NO, with funure applications to other species).

\section{Advanced Materials}

Material processing in spacecraft is already a well established field, with recognized potential for commercialization $^{25,26}$ The non-buoyant environment promotes the study and application of physical processing, with such benefits as precise phase separations, homogeneous compositional control, uniform large crystal growth, and containerless processing.

The predominant role of combustion in material syntheses and processing is certainly recognized, but the wide range of potential applications (and the influence of gravity) is often overlooked. Combustion synthesis, for example, is the basis for the commercial production of many commodity and reagent gases, powders, ceramics, plastics, and coatings. Gravity is inherent in these processes, enhancing or inhibiting the actions of contacting devices, scrubbers, separators, and heat and mass exchangers. Even small-scale microgravity-combustion studies can aid the understanding and improvement of these operations by idealizing the systems, simplifying the analysis of reactions and modeling, and by aiding the evaluation of alternative or innovative techniques.

The current thrust in microgravity-combustion applications relative to material syntheses obviously concentrates on methods yielding products of high unit value, such as advanced ceramics, intermetallics, or fullerenes. As an example, one can cite the progress in self-propagating hightemperature synthesis (SHS). ${ }^{27}$ The SHS process is based on highly exothermic, self-sustaining reactions for the efficient production of many refractory, high-strength, and specialized ceramic, alloy, and composite materials from metal-powder reagents. In normal gravity, the SHS reactions, which generate high temperatures and fluid phases, are prone to gravity-driven flows, density gradients, and product segregation. Microgravity, therefore, offers an environment for study and process analysis free from these disturbances. ${ }^{2}$ Microgravity experiments can verify analytical predictions, and they can lead to a better understanding of the kinetics of the reaction and the phase control of the products.

Potential products obtained by SHS reactions may include ceramic fibers and whiskers, porous materials for filters and medical implants, glasses, as well as monolithic intermetallics. An interesting illustration of heterogeneous materials produced by SHS and the influence of gravity on the product morphology is shown in fig. 6, taken from the work of A.S. Shteinberg of the Russian Institute of Structural Macrokinetics. In this example, titanium carbide is formed as a "foam" product through unconstrained expansion during the reaction from the elements. Regardless of the reaction orientation, gravity forces inhibit the expansion. In microgravity, a fully expanded product is obtained.

Particle synthesis in flames also offers the promise of low-cast mamifacuring of non-oxide powders, such as uniform silicon carbide particles. This effort could be linked to the study of ash formation in combustion processes.

The CCACS has plans for initial projects in the following areas: 1) combustion synthesis of powders, whiskers, and fibers; 2) combustion synthesis of intermetallics, composites, and glasses; 3) synthesis of metal-matrix composite materials for advanced aerospace applications and components; 4) synthesis of porous NiTi materials for filters and bone-replacement components; 5) exothermic and microwave brazing processes for the attachment of diamond, thermally stable-product (TSP) cutters to petroleum drill bits; and 6) synthesis of high-purity specialty glasses for fibers.

\section{Concluding Remarks}

The non-convective, microgravity environment associated with orbiting spacecraft offers advantages for research that have greatly increased the fundamental knowledge of combustion science. Because of the great economic importance of combustion processes in practice, there is strong motivation to pursue the commercial applications of the research findings. Examples of technology developments now actively underway, and described in this paper, include spacecraft and terrestrial fire safety, combustors for use in propulsion and power systems, applied sensors and controls 
(including diagnostic instrumentation), and advanced materials developed with self-propagating high-temperature synthesis (SHS).

\section{References}

1.Law, C.K; and Faeth, G.M.: Opportunities and Challenges of Combustion in Microgravity. Prog. Energy Comb. Science., vol. 20, 1994, pp. 65-113.

2. Microgravity Combustion Science: 1995 Program Update. NASA TM 106858, April 1995.

3. Friedman, R.; and Urban, DL.: Contributions of Microgravity Test Results to the Design of Spacecraft Fire Safety Systems. AIAA Paper 93-1152, Feb. 1993.

4. Lekan, J.; Neumann, E.S.; and Sotos, R.G.: Capabilities and Constraints of NASA's Ground-Based Reduced Gravity Facilities, in 2nd Internat. Microgravity Comb. Workshop. NASA Conf. Publ. CP-10113, Feb. 1993, pp. 45-60.

5. Friedman, R.: Fire Safety Practices and Needs in Human Crew Spacecraft. Jour. Appl. Fire Safety, vol. 2, no. 3, 1992-3, pp. 243-259.

6. Greenberg, P.S.; Sacksteder, K.R.; and Kashiwagi, T.: Wire Insulation Flammability Experiment: USML-1 1 Year Post Mission Summary, in Frazier, D.O.; Lehoczky, S.L.; and Baugher, C.R. eds.: Joint Launch + One Year Sci. Review of USML-1 and USMP-1 with the Micrograv. Meas.Group. NASA Conf. Publ. CP-3272, vol. II, May 1994, pp. 631-655.

7. Rygh, K.: Fire Safety Research in Microgravity: How to Detect Smoke and Flames You Cannot See. Fire Technol., vol. 31, May 1995, pp. 175-185.

8. Olson, S.L.; Ferkul, P.V.; and Tien, J.S.: Near-Limit Flame Spread Over a Thin Solid Fuel in Microgravity. Twenty-Second Symp.(International) on Comb. The Combustion Inst., Pittsburgh, 1988, pp. 1213-1222.

9. Grayson, G.; et al.: Flame Spreading Over a Thin Solid in Low-Speed Concurrent Flow-Drop Tower Experimental Results and Comparison with Theory. Micrograv. Sci. Technol., vol. VII, No. 2, June 1994, pp. 187-195.

10. Ramachandra, P.A.; et al.: The Behavior of Flames Spreading Over Thin Solids in Microgravity. Comb. and Flame, vol. 100, 1995, pp. 71-84.
11. Ito, H.; Fujita, O.; and Ito, K.: Agglomeration of Soot Particles in Diffusion Flames Under Microgravity. Comb. and Flame, vol. 99, 1994, pp. 363-370.

12. Choi, M.Y.; et al.: Soot Agglomeration in Isolated, Free Droplet Combustion. AIAA Paper 93-0823, Jan. 1993.

13. Paul, MR; et al.: The Morphological Description of Particles Generated from Overheated Wire Insulations in Microgravity and Terrestrial Environments, in Sadhal, S.S.; and Hashemi, A.; eds.: Heat Transfer in Microgravity Systems - 1993. ASME HTD, vol. 235, Aug. 1993, pp. 59-66.

14. Urban, D.L; et al.: Smoke Detection in Low-G Fires, in Ross, H.D., ed.: 3rd Internat. Microgravity Comb. Workshop. NASA Conf. Publ. CP-10174, Aug. 1995, pp. 175-180.

15. Priem, RJ.: Sudy of Industry Requirements That Can Be Fulfilled by Combustion Experimentation Aboard Space Station. NASA CR-180854, March 1988.

16. Tien, J.S.: The Possibility of a Reversal of Material Flammability Ranking from Normal Gravity to Microgravity. Comb. and Flame, vol. 80, 1990, pp. 355-357.

17. Todd, P.; et al.: Physics, Chemistry and Pulmonary Sequelae of Thermodegradation Events in Long-Mission Space Flight. SAE Tech. Paper 932144, July 1993.

18. Tapscoth, R., ed.: Chemical Options to Halons for Aircraft Use. DOT/FAA/CT-95/9, Feb. 1995.

19. Lyons, V.J.; and Niedzwiecki, R.W.: Combustor Technology for Future Small Gas Turbine Aircraft. NASA TM 106312, Aug. 1993.

20. Ziemianski, J.A.; and Ball, C.L.: Propulsion Technology Challenges for Turn-of-the-Century Commercial Aircraft, NASA TM 106192, June 1993.

21. Bedat, B.; Kostiuk, L.W.; and Cheng, R.K.: Coupling of Wrinkled Laminar Flames with Gravity, in Ross, H.D., ed:3rd Internat. Microgravity Comb. Workshop. NASA Conf. Publ. CP-10174, Aug. 1995, pp. 395-400.

22. Kostiuk, L.W.; and Cheng, R.K.: Apparatus and Method for Burning a Lean, Premixed Fuel/Air Mixture with Low NOx Emission. U.S. Patent No. 5,516,280, May 14, 1996.

23. Haggerty, JJ.: Spinoff 1995. NASA NP-217, 1996.

24. Weiland, K.J.: Qualitative and Quantitative Imaging in Microgravity Combustion, in Ross, H.D., ed.: 3rd Internat. Microgravity Comb. Workshop. NASA Conf. Publ. CP-10174, Aug. 1995, pp. 291-302. 
25. Bayuzick, RJ.: Space Processing of Metals and Alloys, in Shahrokhi, F.; Chao, C.C.; and Harwell, K.E., eds.: Commercial Opportunities in Space. Prog. in Aero. and Astro,, vol. 110, AIAA, Washington, 1988, pp. 137-160.

26. Whitten, R.P.; and Gabris, E.A.: Commercial Space Processing. AlAA Paper 95-0389, Jan. 1995.
27. Merzhanov, A.G.: Theory and Practice of SHS: Worldwide State of the Art and the Newest Results. Internat. Jour. of Self-Propagating High-Temp. Synthesis, vol. 2, 1993, pp. 113-158.

28. Hunter, K.R.; and Moore, JJ.: The Effect of Gravity on the Combustion Synthesis of Ceramic and CeramicMetal Composites. Jour. Mater. Synth. Proc., vol. 2, 1994, pp. 355-365. 
Table 1

Microgravity-Combustion Experiments for Potential Commercial Applications Arranged by interest Group from 1988 Survey

\begin{tabular}{|l|l|}
\hline \multicolumn{1}{|c|}{ INTEREST GROUP } & \multicolumn{1}{c|}{ POTENTIAL APPLICATIONS } \\
\hline Fire Safety for Space Applications & $\begin{array}{l}\text { - Material Flammability Evaluation Under Low-Flow } \\
\text { Forced Convection } \\
\text { - Fire Event Definition and Detection } \\
\text { - Fire Control and Post-Fire Cleanup }\end{array}$ \\
\hline Fire Safety for Terrestrial Applications & $\begin{array}{l}\text { - Dust Explosions } \\
\text { - Fire Signatures } \\
\text { - Fire Suppression } \\
\text { - Fire Safety in Transportation or Isolated Environments }\end{array}$ \\
\hline Propulsion and Power-Industrial Burners & $\begin{array}{l}\text { - Simplified Models/Experiments for Combustion } \\
\text { Systems } \\
\text { - Isolated droplets and particles } \\
\text { - Premixed gases } \\
\text { - Laminar and turbulent diffusion flames } \\
\text { - Demonstration of Radiant and Catalytic Burners - } \\
\text { Non-Convective Environments }\end{array}$ \\
\hline Pollution Control & $\begin{array}{l}\text { - Soot Generation, Control, and Measurement } \\
\text { - NOx Generation and Control } \\
\text { - Fire Suppression and Control of Agents and Products }\end{array}$ \\
\hline
\end{tabular}

Table 2

Microgravity Combustion Applications

Arranged by Combustion Mode from 1996 Commercial Center Evaluation

\begin{tabular}{|l|l|}
\hline \multicolumn{1}{|c|}{ COMBUSTION TOPIC } & \multicolumn{1}{c|}{ POTENTIAL APPLICATIONS } \\
\hline Lean Premixed Combustion & $\begin{array}{l}\text { - Low-Emission Domestic/lndustrial Heat } \\
\text { Appliances } \\
\text { - Low-Emission Propulsion and Ground Power } \\
\text { Systems }\end{array}$ \\
\hline Droplet Combustion & $\begin{array}{l}\text { - Understanding Fuel Spray Combustion for } \\
\text { Improved Efficiency, Reduced Soot Emissions } \\
\text { - Preventing Explosions in Grain Elevators, Mines }\end{array}$ \\
\hline Soot Formation/Agglomeration & $\begin{array}{l}\text { - Carbon-Producing Industry Applications for Paint } \\
\text { Production, Tires } \\
\text { - Reduction of Soot Emissions }\end{array}$ \\
\hline $\begin{array}{l}\text { Smoldering and Flame Spread in Solids and Liquid } \\
\text { Pools }\end{array}$ & $\begin{array}{l}\text { - Fire Safety } \\
\text { - Fuel Spill Cleanup } \\
\text { - Gas Turbine and Internal Combustion Engines }\end{array}$ \\
\hline Combustion Synthesis of Novel Materials & $\begin{array}{l}\text { - Fabricating Structures in Space } \\
\text { - Advanced Composites, Ceramics with Uniform } \\
\text { Properties } \\
\text { - Porous Materials for Filters, Bone Replacement }\end{array}$ \\
\hline
\end{tabular}




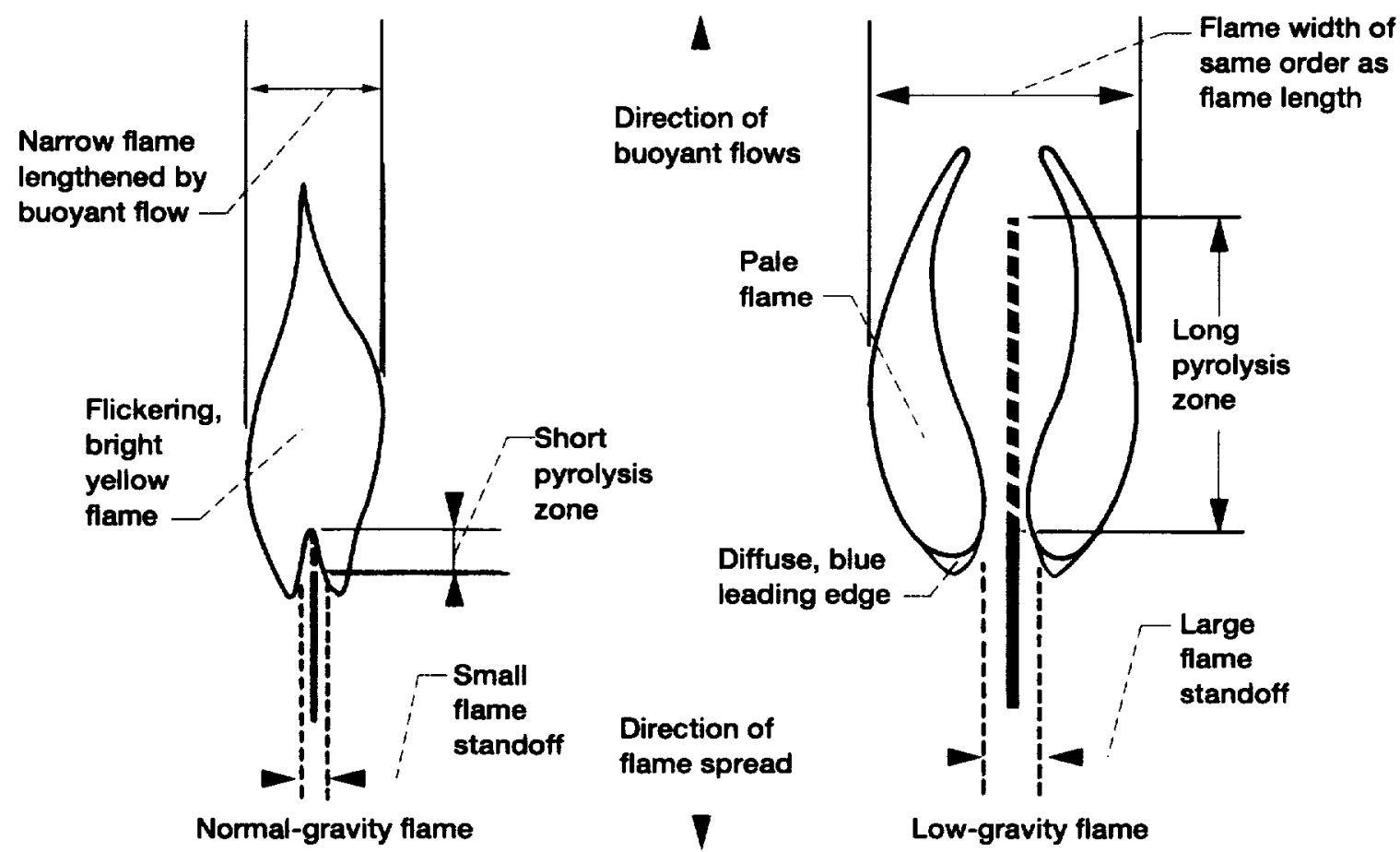

Figure 1.-Typical flame appearance on burning thin solid fuels, paper for example.
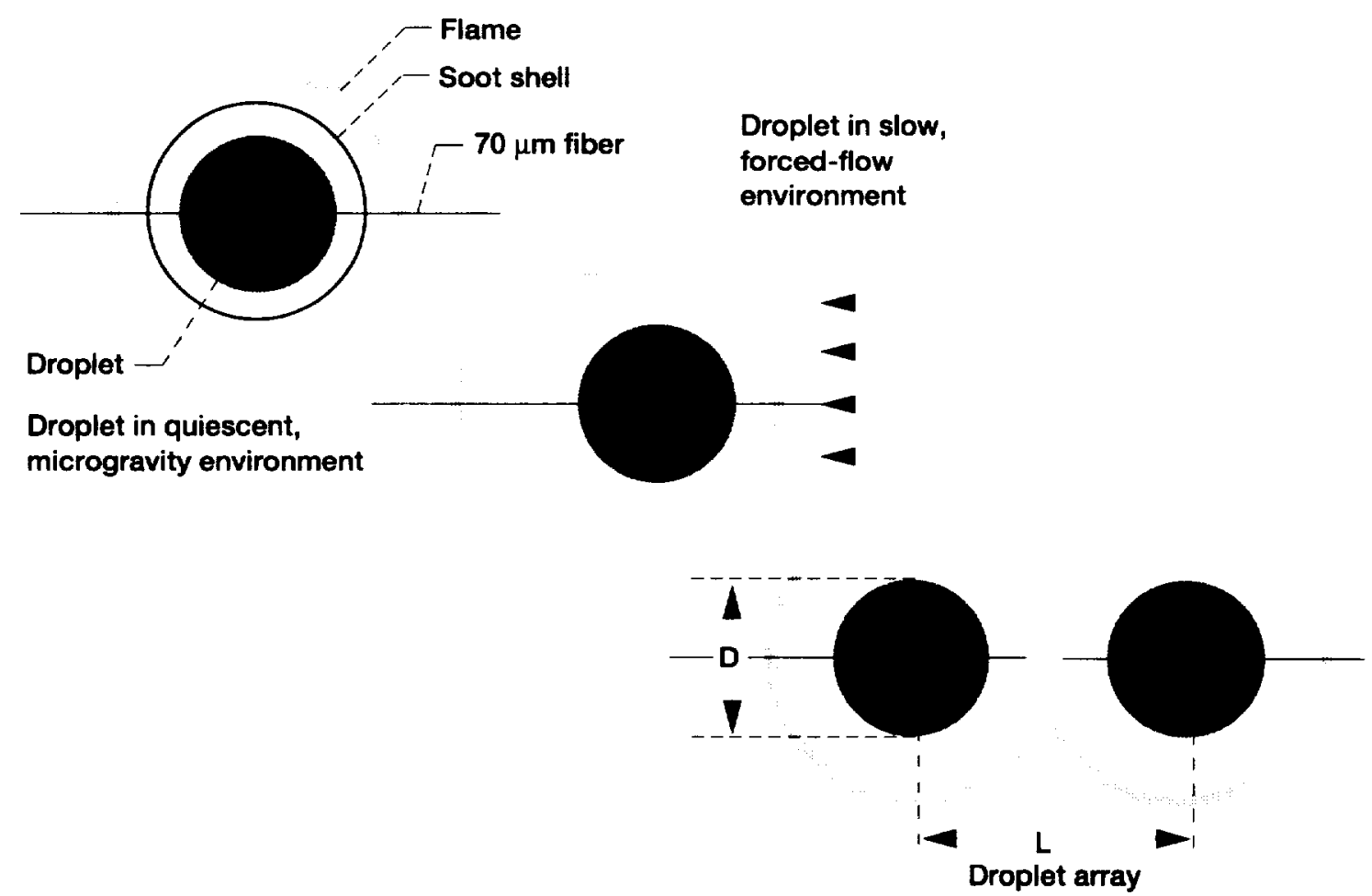

Figure 2.-Typical flame appearance on burning hydrocarbon droplets, stabilized on ceramic fibers, observed in microgravity. 


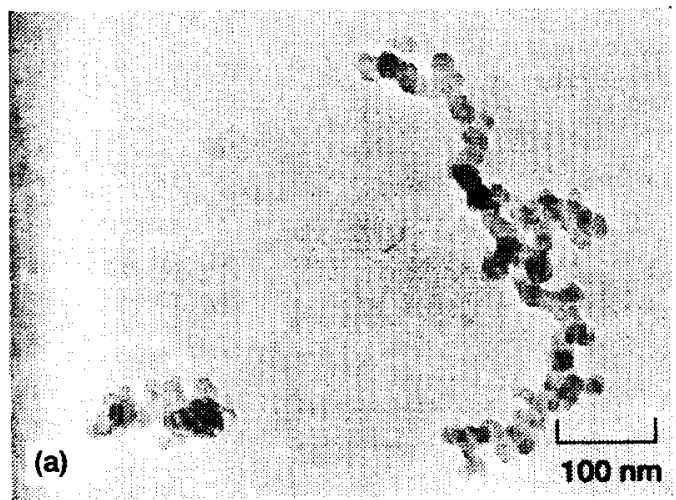

(b)

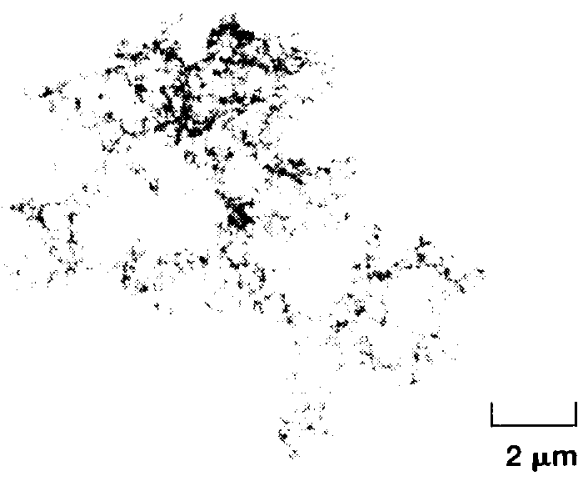

Figure 3.-Examples of soot-particle aggregates collected over ethylene diffusion bumers. (Note the differing scales of magnification. (a) Normal gravity $\times 116,000$. (b) Low gravity $\times 4000$.

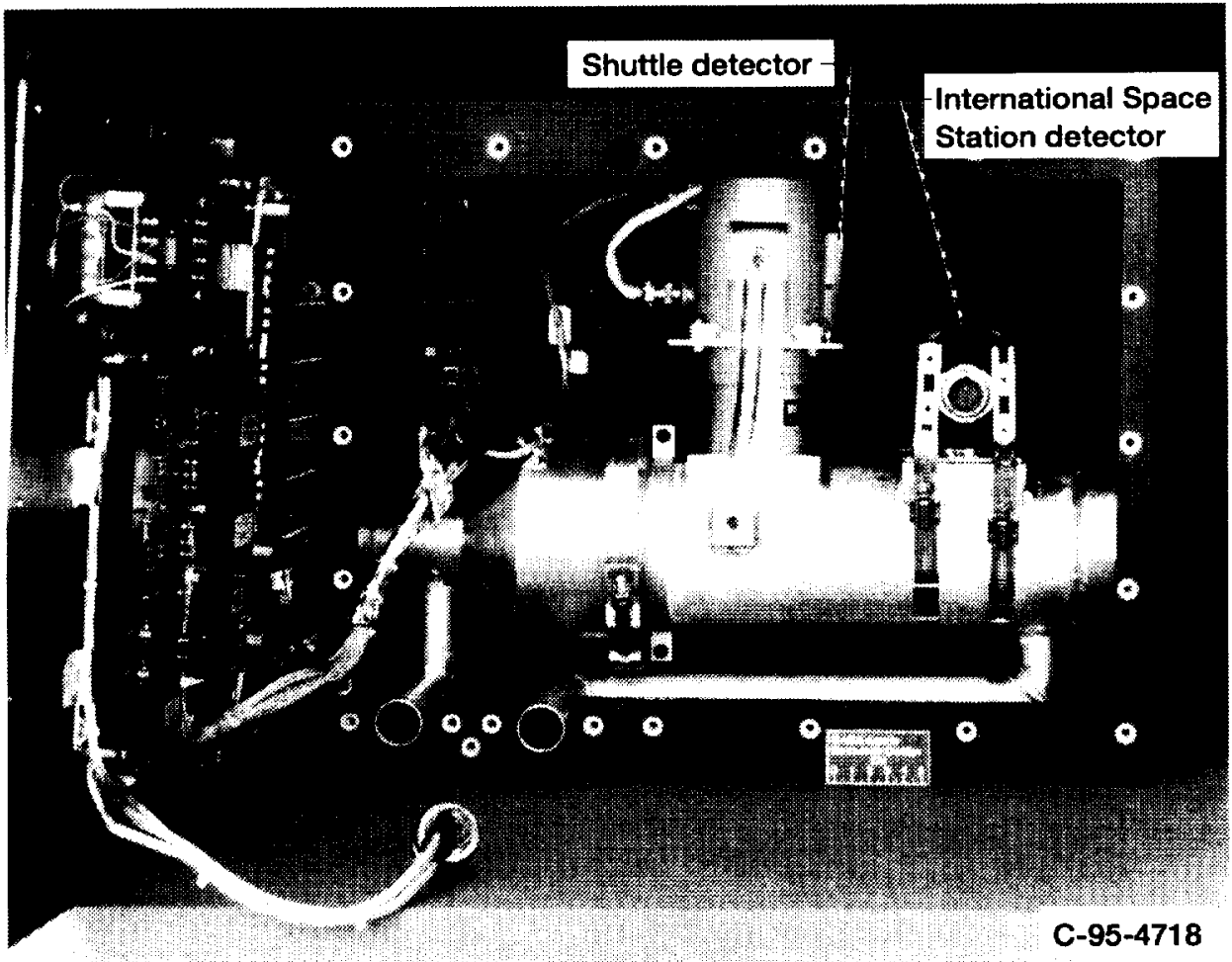

Figure 4.-Spacecraft smoke detectors installed on flow duct for Shuttle experiment of Febuary 1996. 


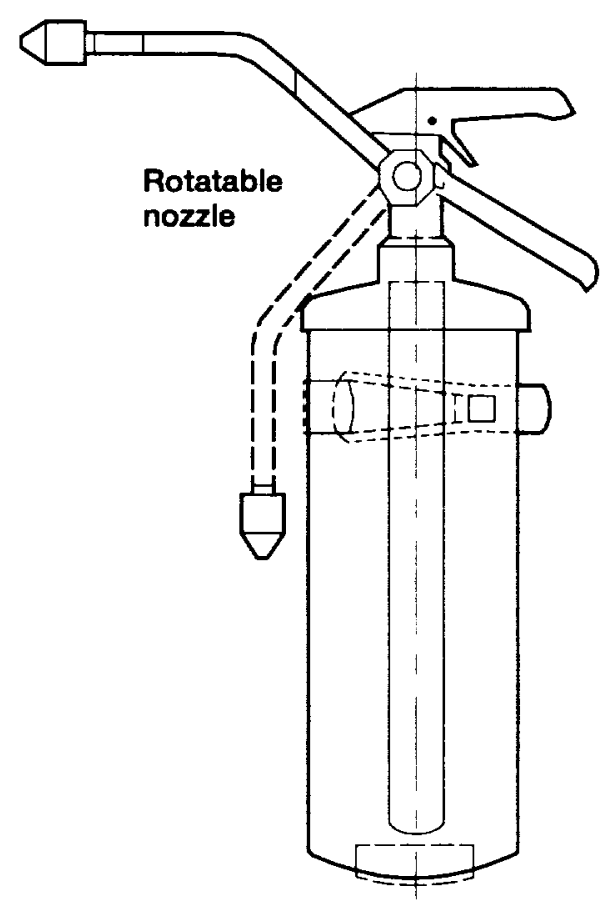

Portable:

Halon charge 3 kg; discharge time 30 sec

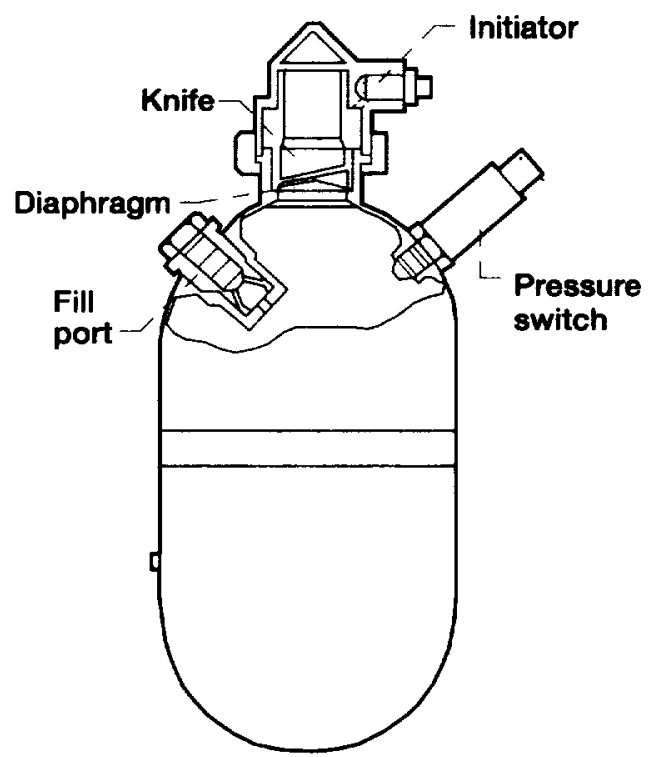

Fixed:

Halon charge $1.7 \mathrm{~kg}$; discharge time $1 \mathrm{sec}$

Figure 5.-Shuttle fire extinguishers, charged with Halon 1301

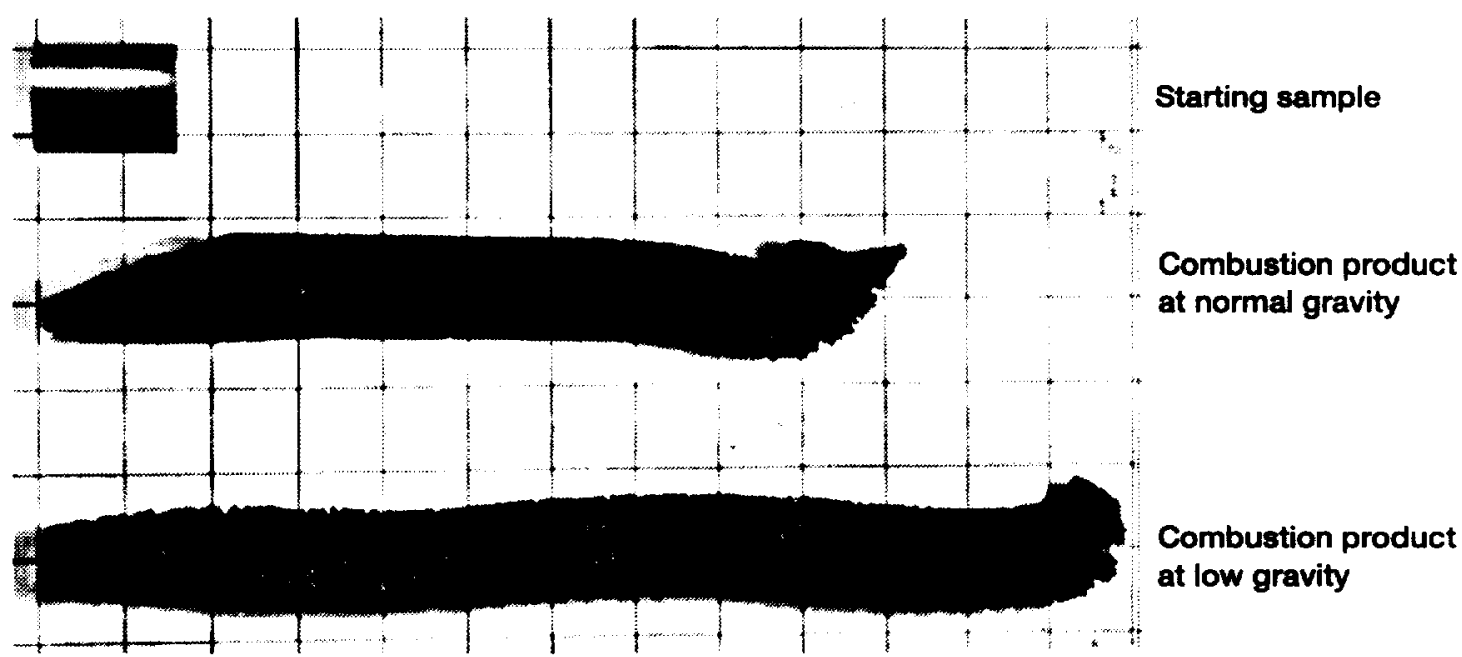

Figure 6.-Examples of product of expanded titanium carbide formed through combustion synthesis. 
Public reporting burden for this collection of information is estimated to average 1 hour per response, including the time for reviewing instructions, searching existing date sources, gathering and maintaining the data needed, and completing and reviewing the collection of information. Send comments regarding this burden estimate or any other aspect of this collection of information, including suggestions for reducing this burden, to Washington Headquarters Services, Directorate for Information Operations and Peports, 1215 Jefferson Davis Highway, Suite 1204, Arlington, VA 22202-4302, and to the Office of Management and Budget, Paperwork Reduction Project (0704-0188), Washington, DC 20503.

\begin{tabular}{|l|l|l}
\hline 1. AGENCY USE ONLY (Leave blank) & $\begin{array}{c}\text { 2. REPORT DATE } \\
\text { August } 1996\end{array}$ & $\begin{array}{c}\text { 3. REPORT TYPE AND DATES COVERED } \\
\text { Technical Memorandum }\end{array}$
\end{tabular}

4. TITLE AND SUBTITLE

5. FUNDING NUMBERS

Potential Commercial Applications From Combustion and Fire Research in Space

Robert Friedman and Valerie J. Lyons

WU-962-22-00

7. PERFoRMING ORGANIZATION NAME(S) AND ADDRESS(ES)

8. PERForming ORganization REPORT NUMBER

National Aeronautics and Space Administration

Lewis Research Center

Cleveland, Ohio 44135-3191

$\mathrm{E}-10324$

9. SPONSORING/MONITOAING AGENCY NAME(S) AND ADDRESS(ES)

10. SPONSORINGMONITORING AGENCY REPORT NUMBER

National Aeronautics and Space Administration

Washington, DC 20546-0001

NASA TM-107260

AIAA-96-4439

11. SUPPLEMENTARY NOTES

Prepared for the 1996 Space Processing and Technology Conference, sponsored by the American Institute of Aeronautics and Astronautics, Huntsville Alabama, September 24-26, 1996. Responsible person, Robert Friedman, organization code $6711,(216) 433-5697$.

12a. DISTRIBUTION/AVAILABILITY STATEMENT 12b. DISTRIBUTION CODE

Unclassified - Unlimited

Subject Category 85

This publication is available from the NASA Center for AeroSpace Information, (301) 621-0390.

13. ABSTRACT (Maximum 200 words)

The near-zero (microgravity) environment of orbiting spacecraft minimizes buoyant flows, greatly simplifying combustion processes and isolating important phenomena ordinarily concealed by the overwhelming gravity-driven forces and flows. Fundamental combustion understanding-the focus to date of the NASA microgravity-combustion program-has greatly benefited from analyses and experiments conducted in the microgravity environment. Because of the economic and commercial importance of combustion in practice, there is strong motivation to seek wider applications for the microgravity-combustion findings. This paper reviews selected technology developments to illustrate some emerging applications. Topics cover improved fire-safety technology in spacecraft and terrestrial systems, innovative combustor designs for aerospace and ground propulsion, applied sensors and controls for combustion processes, and self-sustaining synthesis techniques for advanced materials.

14. SUBJECT TERMS

Combustion; Combustion control; Fire prevention; Reduce gravity; Space commercialization; Space processing

15. NUMBER OF PAGES 14

16. PRICE CODE A03

\begin{tabular}{c|c|c|}
\hline $\begin{array}{c}\text { 17. SECUATY CLASSIFICATION } \\
\text { OF REPOAT } \\
\text { Unclassified }\end{array}$ & $\begin{array}{c}\text { 18. SECURTY CLASSIFICATION } \\
\text { OF THIS PAGE } \\
\text { Unclassified }\end{array}$ & $\begin{array}{c}\text { 19. SECURITY CLASSIFICATION } \\
\text { OF ABSTRACT } \\
\text { Unclassified }\end{array}$
\end{tabular}

